\title{
A nanofibrous membrane fluorescent sensor for fluoride ions prepared by electrospinning and host-guest interaction
}

\author{
Huan Zhang ${ }^{1,2}$, Chen Zhou ${ }^{1,2}$, Jing Sun ${ }^{1,2}$, Xiao Li $^{1,2}$, Juan Tang ${ }^{1,2}$
}

\footnotetext{
${ }^{1}$ School of Chemistry \& Environmental Engineering, Changchun University of Science and Technology,Changchun, 130022, People's Republic of China.

2 Jilin Provincial Science and Technology Innovation Center of Optical Materials and Chemistry, Changchun, 130022, People's Republic of China.

e-mail: zhouchen@cust.edu.cn
}

\begin{abstract}
A novel inclusion complexes nanofibrous membrane fluorescent sensor was prepared for recognizing $\mathrm{F}^{-}$via electrospinning and host-guest interaction. The host $\alpha$-cyclodextrin on the surface of the electrospun nanofiber membrane is assembled into the guest azobenzene molecule which modified with $\mathrm{F}^{-}$fluorescent probe, and the formation of the inclusion complex is fixed on the surface of the nanofibrous membrane without external force, to prepare a novel surface controllable composite nanofiber membrane for $\mathrm{F}^{-}$detection. The inclusion complexes nanofibrous membrane exhibited favourable sensitivity and selectivity for FThe introduction of $\mathrm{F}^{-}$would result in notable fluorescent decreasing of the membrane, but the other most common anions would not disturb the detection of $\mathrm{F}^{-}$. Moreover, this nanofibrous membrane was not only a fluorescent sensor for detecting $\mathrm{F}^{-}$, but also a good adsorbent for $\mathrm{F}^{-}$in solution.
\end{abstract}

Keywords: Host-guest interaction, Nanofibrous membrane, Fluorescent sensor, Fluoride ions, Adsorbent

\section{INTRODUCTION}

$\mathrm{F}^{-}$is a very common anion in the environment, it always exists in the form of various compounds. Moreover, $\mathrm{F}^{-}$is also widely used in industrial production, such as manufacture of plastics and rubber, the production of rodenticide pharmaceutical and pesticide [1]. The $\mathrm{F}^{-}$content in human body is about $2.6 \mathrm{~g}$, and $95 \%$ of them are distributed in bones and teeth to enhance their structure stability, in the second distributed in hair and nails, and microscale in organs [2]. The adsorption of $\mathrm{F}^{-}$in the human body is mainly in water, food and skin, the soluble $\mathrm{F}^{-}$in drinking water is almost absorbed by the small intestine and stomach, and the absorption rate of $\mathrm{F}^{-}$in food is about $50 \%$, moreover, $\mathrm{F}^{-}$can be absorbed in human body by skin and transported to bone through blood $[3,4]$. Excessive $\mathrm{F}^{-}$in the human body will disturb the metabolism of calcium and phosphorus, then damage to skeleton, cardiovascular and nervous system, and even result in pharyngitis, laryngitis, tracheitis, autonomic nerve dysfunction and acid erosion [5]. It is vital important to develop chemosensors for $\mathrm{F}^{-}$in the current environment.

With the rapid expansion of fluorescence detection technique, more and more fluorescent sensors were applied to the composite material field, and nanofiber materials have attracted extensive attention due to their good properties [6,7]. Electrospinning is a mature technology for fabricating nanofibrous membrane, the membrane prepared in this way is provided with many obvious structural superiority, such as large specific surface area and high porosity, meanwhile the porous reticulation structure is able to promote the diffusion rate of analyte inside nanofibrous membrane effectively, advance the interaction between the analyte and the functional sensors spreaded in the membrane [8]. This kind of material is very suitable for the construction of fluorescence sensors membrane. The host-guest interactions have been one of the hottest topics in supramolecular chemistry. By choosing the proper host and guest molecules, such as $\alpha$ - cyclodextrin ( $\alpha$-CD) (host) and azobenzene (guest), the self-assembled systems provide the possibility of immobilizing guest deriva- 
tives on a variety of substrates, but host-guest interaction was infrequently reported in the preparation of inclusion complexes nanofibrous membrane in previous work [9]. In this research, we fabricate the nanofibrous membrane fluorescent sensor for $\mathrm{F}^{-}$via host-guest interaction and electrospinning. The guest azobenzene modified with $\mathrm{F}^{-}$fluorescent probe is assembled into the host $\alpha$-cyclodextrin molecule on the surface of the electrospun nanofiber membrane, it is concluded that the formation of the inclusion complex is fixed on the surface of the nanofibrous membrane without external force, to prepare a novel surface controllable composite nanofiber membrane for $\mathrm{F}^{-}$detection, in addition, this study also expands the method for the preparation of composite nanofiber membrane.

\section{MATERIALS AND METHODS}

All the chemical reagents and solvents used for synthesis were obtained from commercial suppliers and used without further purification. Solvents for spectra detection was HPLC reagent without fluorescent impurity. Solutions of different ions in titration and selectivity experiments were prepared with tetrabutylammonium salt of anions $\left(\mathrm{CN}^{-}, \mathrm{F}^{-}, \mathrm{Cl}^{-}, \mathrm{AcO}^{-}, \mathrm{NO}_{3}^{-}, \mathrm{HSO}_{4}^{-}, \mathrm{I}^{-}, \mathrm{H}_{2} \mathrm{PO}_{4}^{-}, \mathrm{ClO}_{4}^{-}, \mathrm{PO}_{4}{ }^{3-}, \mathrm{SO}_{4}{ }^{2-}, \mathrm{HPO}_{4}{ }^{2-}\right.$ and $\left.\mathrm{HS}^{-}\right)$in HEPES-NaOH buffer solution at $\mathrm{pH} 7.1$, all $\mathrm{pH}$ measurements were performed with a PHS-3C meter, the stock solution of probe was prepared in ethanol. The test samples were prepared by adding accurate amounts of ions stock into corresponding concentration solution of probe $\left[\mathrm{CH}_{3} \mathrm{CN}: \mathrm{H}_{2} \mathrm{O}=1\right.$ : 1, $\left.\mathrm{pH}=7.1\right]$. For fluorometric analysis, the fluorescence spectra measurements were performed on a Hitachi F-4500 spectrofluorimeter, the excitation wavelength was set as $319 \mathrm{~nm}$, and emission wavelength was collected from 450 to $675 \mathrm{~nm}$; both the excitation and emission slit widths were set as $5 \mathrm{~nm}$ and $5 \mathrm{~nm}$, respectively. The FTIR measurements were performed on a BIO-RAD FTS135 Fourier Transform Infrared Spectrometer, KBr as tablet method with a resolution of $4 \mathrm{~cm}^{-1}$, measuring range 400 4000. The SEM measurements were performed on a JEOL JSM-7610F scanning electron microscope analyzer.

\subsection{Synthesis of intermediate 1 [10]}

4-Bromo-1,8-naphthalic anhydride $(5.51 \mathrm{~g}, 2.33 \mathrm{mmol})$ was dissolved in $150 \mathrm{~mL}$ ethanol at $70{ }^{\circ} \mathrm{C}$, and butylamine $(1.6 \mathrm{~mL}, 22.03 \mathrm{mmol})$ was added dropwise into the solution under stirring. The mixture was refluxed for $2 \mathrm{~h}$ and cool down to $25^{\circ} \mathrm{C}$, then distilled solvent to obtain crude product, the column chromatography was utilized to purify the crude product (EtOH: $\left.\mathrm{CH}_{2} \mathrm{Cl}_{2}=1: 15\right)$ from silica gel, the intermediate 1 was collected as white solid $(3.70 \mathrm{~g}$, yield $52 \%)$. Take the above product $(1.10 \mathrm{~g}, 5.0 \mathrm{mmol})$ and ethanediamine $(1.51 \mathrm{~g}, 25 \mathrm{mmol})$ in $50 \mathrm{~mL}$ ethylene glycol monomethyl ether. The mixture was refluxed for $2 \mathrm{~h}$ then cool down to room temperature, then remove the solvent, the crude product was purified by recrystallization to obtain intermediate 1 as yellow solid (4.60 g, yield $82 \%)$.

\subsection{Synthesis of intermediate 2}

P-amido-azobenzene $(0.70 \mathrm{~g}, 3.60 \mathrm{mmol})$ and triethylamine $(1.1 \mathrm{~mL}, 7.9 \mathrm{mmol})$ were dissolved in $40 \mathrm{~mL}$ diethylene oxide, then took thiophosgene $(0.3 \mathrm{~mL}, 3.70 \mathrm{mmol})$ into the solution under $\mathrm{N}_{2}$ protection. Heating up the mixture to $60{ }^{\circ} \mathrm{C}$ with stirring for $3 \mathrm{~h}$. The solvent was distilled and the crude product was extract with $\mathrm{CH}_{2} \mathrm{Cl}_{2}$ and water with 3 times, collect the organic phase and remove $\mathrm{CH}_{2} \mathrm{Cl}_{2}$, the crude product was purified by column chromatography (petroleum ether: $\mathrm{CH}_{2} \mathrm{Cl}_{2}=1: 1$ ) on silica gel to obtain intermediate 2 as orange crystal $(1.62 \mathrm{~g}$, yield $90 \%)$.

\subsection{Synthesis of intermediate 3}

Intermediate $1(0.75 \mathrm{~g}, 2.5 \mathrm{mmol})$ and intermediate $2(0.58 \mathrm{~g}, 2.5 \mathrm{mmol})$ were dissolved in $50 \mathrm{~mL} \mathrm{DMF}$ at $80^{\circ} \mathrm{C}$ for $8 \mathrm{~h}$, then distilled DMF to obtain crude product, the column chromatography was utilized to purify the crude product ( $\left.\mathrm{MeOH}: \mathrm{CH}_{2} \mathrm{Cl}_{2}=1: 15\right)$ from silica gel, the intermediate 3 was collected as yellow solid $(0.98 \mathrm{~g}$, yield $74 \%)$.

\subsection{Synthesis of PAN-co-AA/ $\alpha-C D$}

Acroleic acid $(3.60 \mathrm{~g}, 0.05 \mathrm{~mol})$ and acrylonitrile $(15 \mathrm{~g}, 0.29 \mathrm{mmol})$ were dissolved in $75 \mathrm{~mL}$ DMF and heated to $50{ }^{\circ} \mathrm{C}$, then PVP $(0.019 \mathrm{~g})$ and $\operatorname{AIBN}(0.186 \mathrm{~g})$ were added into the solution and keep heating for $4 \mathrm{~h}$. Heat the mixture up to $90{ }^{\circ} \mathrm{C}$ for $10 \mathrm{~h}$, then $500 \mathrm{~mL}$ deionized water was taken into the solution, and collected the generated white precipitates. Washed the precipitates with deionized water for 3 times, and dried them under vacuum at $40{ }^{\circ} \mathrm{C}$ for $12 \mathrm{~h}$. The PAN-co-AA was obtained as white solid (18.69 g, yield $38 \%$ ). PAN-co-AA $(5.0 \mathrm{~g})$ was dissolved in $80 \mathrm{~mL}$ DMF. EDCI (19.17 g, $0.1 \mathrm{~mol})$, DMAP (1.22 g, 0.01 mol) and $\alpha$-CD (102.13 g, $0.1 \mathrm{~mol})$ were dissolved in $500 \mathrm{~mL}$ DMF and added dropwise into the PAN- 
co-AA/DMF solution, kept the mixture stirring for $12 \mathrm{~h}$ at room temperature, the solvent was distilled and the crude product was taken into deionized water. Collected the generated white precipitates and washed them with deionized water for 3 times, and dried them under vacuum at $40{ }^{\circ} \mathrm{C}$ for $12 \mathrm{~h}$ to obtain PAN-co$\mathrm{AA} / \alpha-\mathrm{CD}(11.05 \mathrm{~g})$.

\subsection{Preparation of PAN-co-AA/a-CD nanofibrous membrane [11]}

PAN-co-AA/ $\alpha-C D(2.0 \mathrm{~g})$ was dissolved in DMF $(8.0 \mathrm{~g})$ for rapidly stirring $24 \mathrm{~h}$ at $25{ }^{\circ} \mathrm{C}$. The resulting 20. wt\% precursor solution clear homogenous solution was utilized for electrospinning the nanofibrous membrane. The device for electrospinning process was illustrated as Scheme 2, it was comprised of high - voltage supply, syringe and aluminum foil receiver. In the course of the electrospinning, the high-voltage supply was set as $18 \mathrm{kV}$, the syringe was at a distance of $15 \mathrm{~cm}$ from the aluminum foil, the velocity of spinning was controlled by a microinjector at $4 \mathrm{~mL} \mathrm{~h}^{-1}$, and the experimental environment is adjusted to $25^{\circ} \mathrm{C}$ by air conditioning. After about $2.5 \mathrm{~h}$, the nanofibrous membrane completely covered in the receiver, then picked up the generated membrane by a tweezer from the aluminum foil.

\subsection{Preparation of self assembled inclusion complexes of intermediate 3 and PAN-co-AA/ $\alpha-C D$ nano- fibrous membrane [12]}

Intermediate $3(0.5 \mathrm{~g})$ was dissolved in $100 \mathrm{~mL}$ acetonitrile aqueous solution $\left(\mathrm{CH}_{3} \mathrm{CN}: \mathrm{H}_{2} \mathrm{O}=7: 3\right)$ with stirring at $50{ }^{\circ} \mathrm{C}$. Then PAN-co-AA/ $\alpha-C D$ nanofibrous membrane (size: $1.5 \mathrm{~cm} \times 2 \mathrm{~cm}$ ) was taken into the solution with slowly stirring for $30 \mathrm{~h}$. Then cooled down the mixture to room temperature and alternate washed them with deionized water and methanol for 3 times. After vacuum desiccation, the inclusion complexes of intermediate 3 and PAN-co-AA/ $\alpha-\mathrm{CD}$ nanofibrous membrane was obtained.



Figure 1: Synthesis of intermediate 3

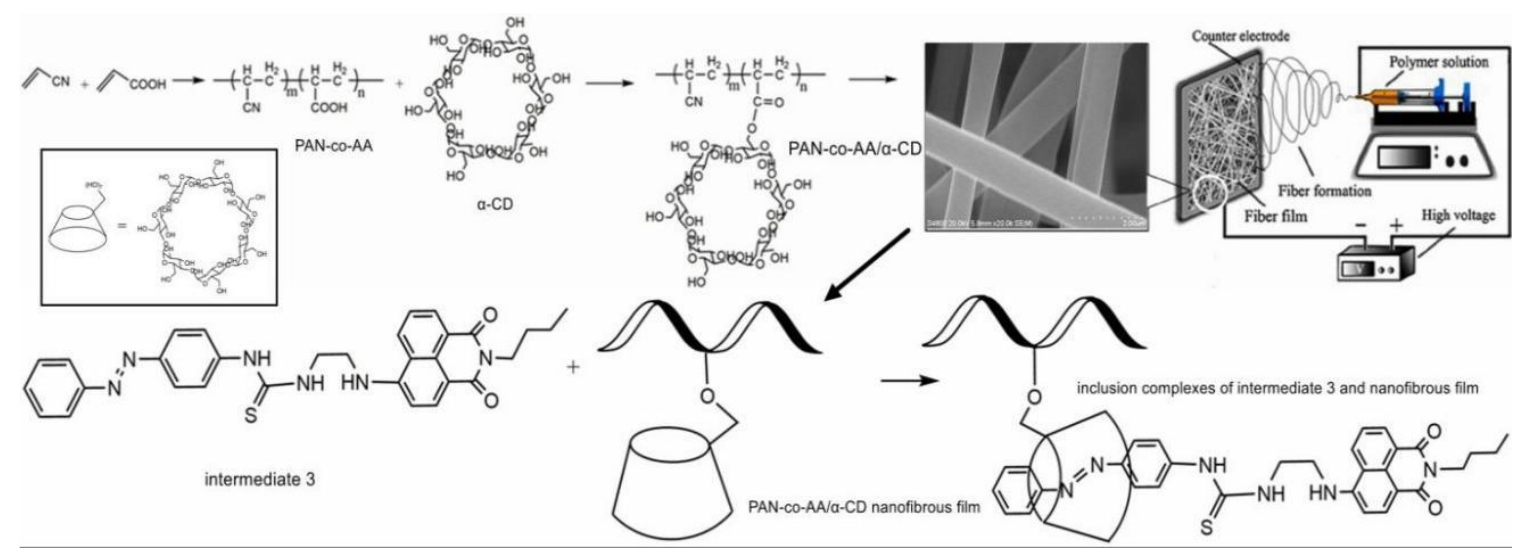

Figure 2: Synthesis of inclusion complexes of intermediate 3 and PAN-co-AA/ $\alpha-C D$ nanofibrous membrane 


\section{RESULTS}

\subsection{FT-IR investigations of inclusion complexes}

FT-IR was utilized to confirm that intermediate 3 was successfully assembled into PAN-co-AA/ $\alpha-C D$ nanofibrous membrane. Figure 3(a), 3(b) and 3(c) displayed the FT-IR spectra of PAN-co-AA/ $\alpha-C D$ nanofibrous membrane, intermediate 3 and inclusion complexes of intermediate 3 and PAN-co-AA/ $\alpha-C D$ nanofibrous membrane, respectively. The bending vibrations at $2923 \mathrm{~cm}^{-1}$ in Figure 3 (a) testified the $-\mathrm{CH}_{2}-$ in $\alpha-\mathrm{CD}$, the band at $1121 \mathrm{~cm}^{-1}$ represented $-\mathrm{OH}$ in $\alpha-\mathrm{CD}$, meanwhile the band at 906 and $1641 \mathrm{~cm}^{-1}$ were ascribed to the stretching vibration of $=\mathrm{C}-\mathrm{H}$ and $\mathrm{C}=\mathrm{C}$ in monomer PAN-co-AA. The characteristic bands around $1660 \mathrm{~cm}^{-1}$ in Figure 3(b) represented the $\mathrm{N}=\mathrm{N}$, which validated azobenzene was successfully introduced in intermediate 3 [13]. The band at 1220 represented $\mathrm{C}=\mathrm{S}$ in the structure, moreover, the band was occurred at $2955 \mathrm{~cm}^{-1}$ proved the existence of $\mathrm{N}-\mathrm{H}$ in intermediate 3 [14]. Furthermore, the above-mentioned characteristic bands in Figure 3(a) and 1(b) all appeared in Figure 3(c), this confirmed that intermediate 3 was successfully assembled into PAN-co-AA/ $\alpha-\mathrm{CD}$ nanofibrous membrane.

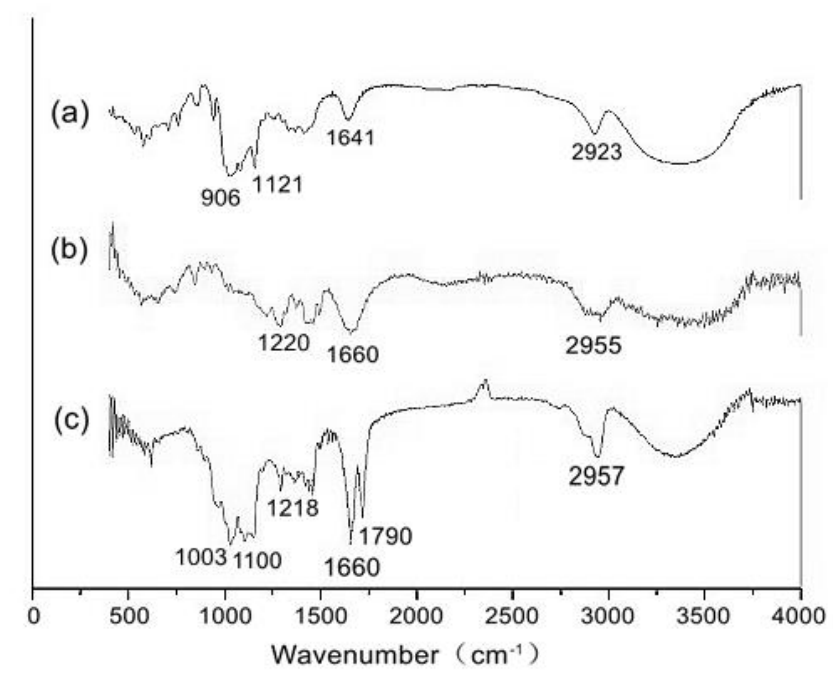

Figure 3: FT-IR spectrum of (a) intermediate 3, (b) PAN-co-AA/ $\alpha-C D$ nanofibrous membrane, and (c) inclusion complexes of intermediate 3 and PAN-co-AA/ $\alpha-\mathrm{CD}$ nanofibrous membrane

\subsection{Morphologies of inclusion complexes nanofibrous membrane}

The SEM images of the inclusion complexes nanofibrous membrane under $50 \mu \mathrm{m}$ and $2 \mu \mathrm{m}$ were shown in Figure 4. It was informed that the inclusion complexes nanofibrous membrane was composed of massive nanofibers in different directions, and no apparent critical fracture or defect were occurred on the nanofiber. The average diameter (D) of nanofibers could be calculated from the following equation (1) [15].

$$
\mathrm{D}=\frac{1}{n} \sum_{i=1}^{n} X_{i}^{*} \frac{B}{L}
$$

where $\mathrm{n}$ represents the number of the nanofibers in SEM images, $\mathrm{B}$ and $\mathrm{L}$ refer to the scale bar and length of the scale bar, respectively. X represents the diameter of independent nanofiber. The average diameter of the nanofiber is calculated to be $0.89 \mu \mathrm{m}$ based on Figure $4 \mathrm{~b}$. Meanwhile, the inclusion complexes nanofibrous membrane take on obvious porous reticulation structure with large specific surface area, this preponderant configuration is able to promote the diffusion rate of $\mathrm{F}^{-}$inside nanofibrous membrane and distinctly accelerate the recognition efficiency [16]. 


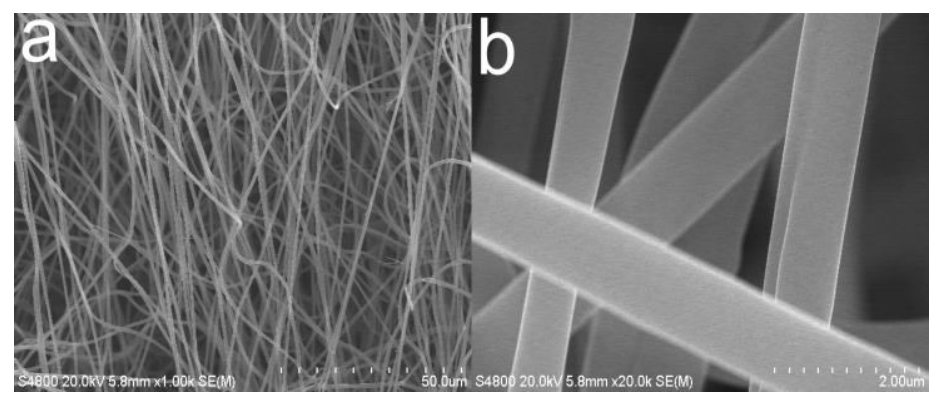

Figure 4: SEM image of the inclusion complexes nanofibrous membrane under different scales (a. SEM image under 50 $\mu \mathrm{m}, \mathrm{b}$. SEM image under $2 \mu \mathrm{m})$

\section{DISCUSSION}

\subsection{Response of the inclusion complexes nanofibrous membrane to $\mathrm{F}^{-}$}

The sensitivity of inclusion complexes nanofibrous membrane toward $\mathrm{F}^{-}$was tested by means of titration experiments. The inclusion complexes nanofibrous membrane were cut to fixed size (size: $0.8 \mathrm{~cm} \times 1.5 \mathrm{~cm}$ ) and immersed in $\mathrm{CH}_{3} \mathrm{CN}$ and buffer solution (HEPES-NaOH, $\mathrm{pH}$ 7.1) in titration experiments $\mathrm{CH}_{3} \mathrm{CN}$ : $\mathrm{H}_{2} \mathrm{O}=1: 1$ ). The fluorescence response upon of the inclusion complexes nanofibrous membrane depend on various concentration of $\mathrm{F}^{-}$was investigated. As shown in Figure 5, the nanofibrous membrane displayed strong fluorescence at $527 \mathrm{~nm}$ (excited at $450 \mathrm{~nm})$, with the increase of $\mathrm{F}^{-}$concentration in the system $(0-$ $200 \mu \mathrm{M})$, the fluorescence intensity at $\mathrm{nm}$ decreased obviously. And we can clearly distinguish the fluorescence change of the membrane before and after added $\mathrm{F}^{-}$under the irradiation of a UV-lamp. This significant decrease of $527 \mathrm{~nm}$ emission is due to the hydrogen bonding of the acceptor moiety distributed on the surface of the membrane, as $\mathrm{F}^{-}$possess strong electronegativity, its introduction forms hydrogen bonds with $\mathrm{H}^{+}$in $\mathrm{NH}$, and the deprotonation of $\mathrm{N}$ leads the electrons transfer to the Homo orbit in the conjugated plane of the excited state of naphthalimide through the PET effect, and this prevents the excited state electrons from moving back, and result in fluorescence decreasing [17]. Moreover, as the velocity of proton transfer is far greater than the general electron coordination velocity, this inclusion complexes nanofibrous membrane have a quick response time to $\mathrm{F}^{-}[18]$.

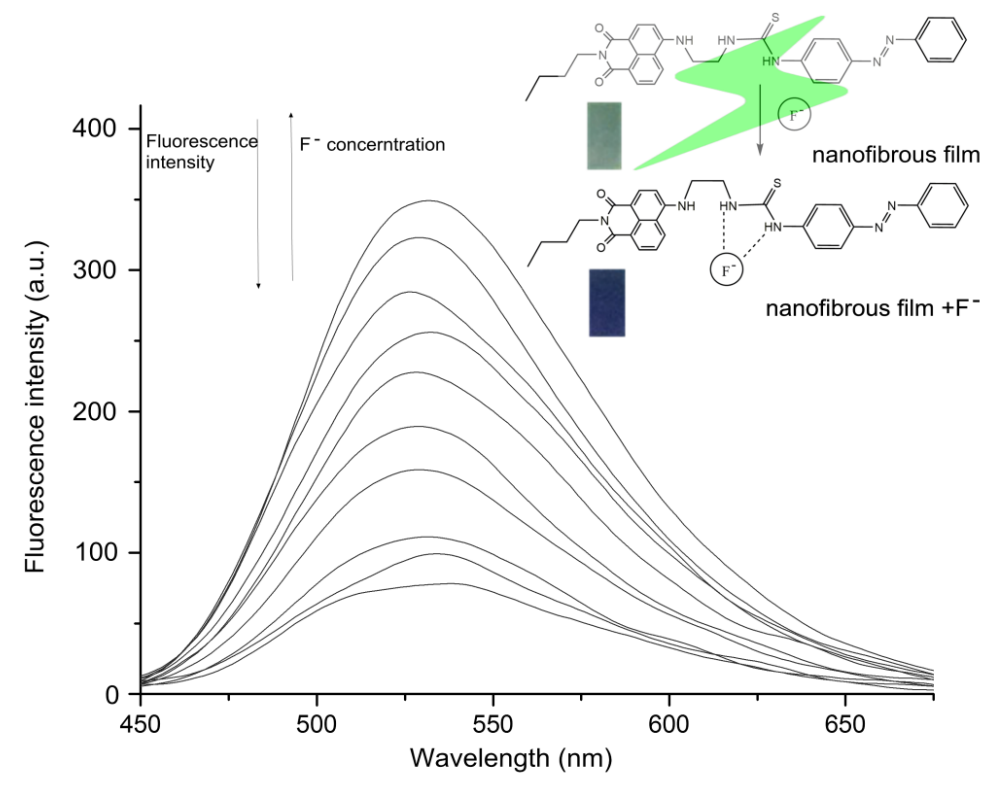

Figure 5: Fluorescence emission spectrum of the inclusion complexes nanofibrous membrane in different $\mathrm{F}^{-}$concentrations in $\mathrm{CH}_{3} \mathrm{CN}-\mathrm{H}_{2} \mathrm{O}$ solution.

\subsection{Selectivity and Competition Experiments}

To examine the selectivity of the inclusion complexes nanofibrous membrane towards $\mathrm{F}^{-}$over the other anions, selectivity experiments and competition experiments were investigated. Some common anions in envi- 
ronmental such as $\mathrm{F}^{-}, \mathrm{Cl}^{-}, \mathrm{Br}^{-}, \mathrm{I}^{-}, \mathrm{CN}^{-}, \mathrm{HSO}_{4}^{-}, \mathrm{H}_{2} \mathrm{PO}_{4}^{-}, \mathrm{AcO}^{-}, \mathrm{NO}_{3}{ }^{-}, \mathrm{ClO}_{4}^{-}, \mathrm{PO}_{4}{ }^{3-}, \mathrm{SO}_{4}{ }^{2-}, \mathrm{HPO}_{4}{ }^{2-}$, $\mathrm{HS}^{-}$were utilized to test their effect of the inclusion complexes nanofibrous membrane. In selectivity experiments, inclusion complexes nanofibrous membrane (size: $0.8 \mathrm{~cm} \times 1.5 \mathrm{~cm}$ ) was infiltrated in a cuvette with $\mathrm{CH}_{3} \mathrm{CN}$ solution, then $100 \mu \mathrm{mol} \mathrm{L}{ }^{-1} \mathrm{~F}^{-}, \mathrm{Cl}^{-}, \mathrm{Br}^{-}, \mathrm{I}^{-}, \mathrm{CN}^{-}, \mathrm{HSO}_{4}^{-}, \mathrm{H}_{2} \mathrm{PO}_{4}^{-}, \mathrm{AcO}^{-}, \mathrm{NO}_{3}^{-}, \mathrm{ClO}_{4}^{-}, \mathrm{PO}_{4}{ }^{3-}, \mathrm{SO}_{4}{ }^{2-}$, $\mathrm{HPO}_{4}{ }^{2-}, \mathrm{HS}^{-}$in HEPES-NaOH buffer solution ( $\mathrm{pH} 7.1$ ) were taken into the cuvette respectively, as illustrated in the black bar of Figure 6, only $\mathrm{F}^{-}$induced an significant fluorescent decrease at $527 \mathrm{~nm}$ in the emission spectra, meanwhile the introduction of other anions did not lead any obvious changes at $527 \mathrm{~nm}$. And we can also clearly distinguish the fluorescent response of different anions on the inclusion complexes nanofibrous membrane under the irradiation of a UV-lamp. Furthermore, the competition experiments were utilized to continue exam the obstruct of the inclusion complexes nanofibrous membrane in the detecting $\mathrm{F}^{-}$


plexes nanofibrous membrane to induce fluorescence decrease, then 1 mmol L-1 $\mathrm{Cl}^{-}, \mathrm{Br}^{-}, \mathrm{I}^{-}, \mathrm{CN}^{-}, \mathrm{HSO}_{4}^{-}$, $\mathrm{H}_{2} \mathrm{PO}_{4}{ }^{-}, \mathrm{AcO}^{-}, \mathrm{NO}_{3}{ }^{-}, \mathrm{ClO}_{4}{ }^{-}, \mathrm{PO}_{4}{ }^{3-}, \mathrm{SO}_{4}{ }^{2-}, \mathrm{HPO}_{4}{ }^{2-}, \mathrm{HS}^{-}$were introduced into the fluorescence-attenuated mixed system respectively. As illustrated in the red bar of Figure 6, the $\mathrm{F}^{-}$still resulted in the similar fluorescence changes, so it was convinced that these anions did not interference the detecting for $\mathrm{F}^{-}$. For rationalizing the good selectivity of the inclusion complexes nanofibrous membrane in detecting $\mathrm{F}^{-}$, we think the acceptor moieties distributed on the surface of nanofibrous membrane possess stronger binding capacity for $\mathrm{F}^{-}$, the binding mode blocks the excited state electrons from moving back to emit fluorescence, but for the other anions, their entries are not provided with these traits to decrease the fluorescence, therefore this causation brings out the favorable selectivity of the inclusion complexes nanofibrous membrane to $\mathrm{F}^{-}$.

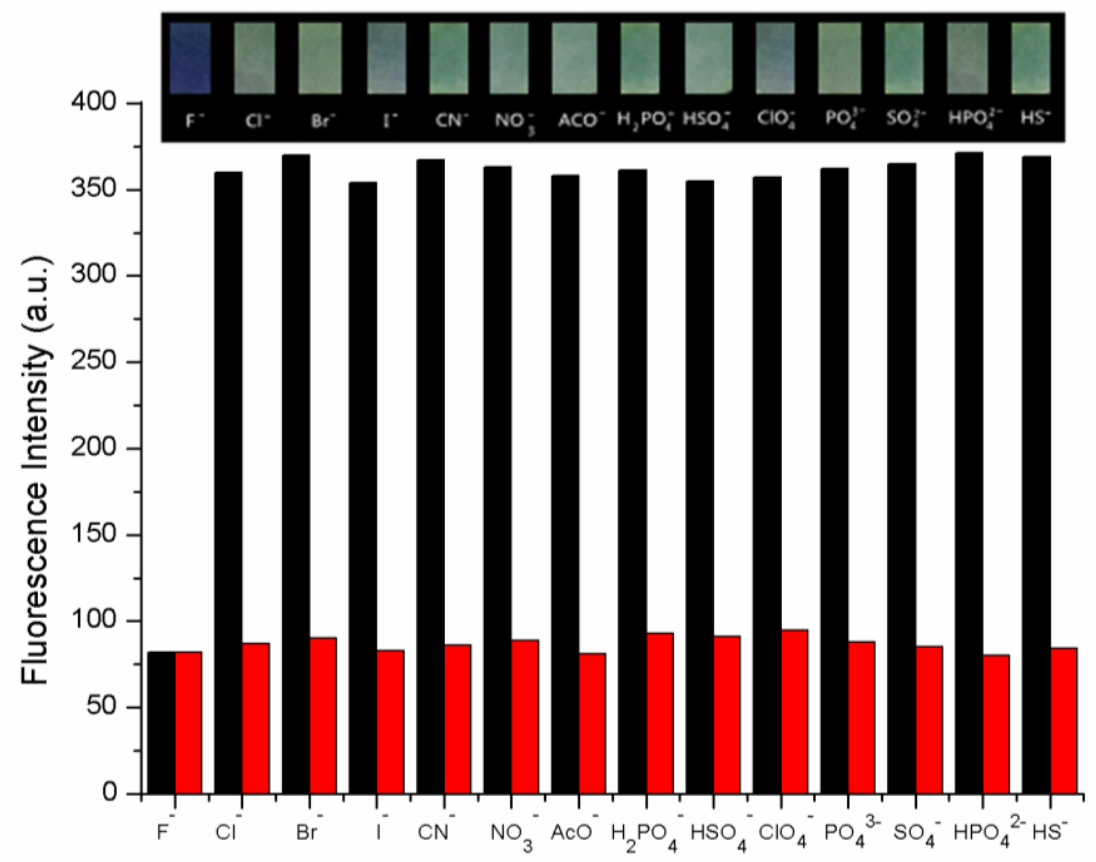

Figure 6: Selectivity experiments of the inclusion complexes nanofibrous membrane (black bar) and competition experiments of the inclusion complexes nanofibrous membrane (red bar)

\subsection{The effect of $\mathrm{pH}$ on the sensing capability of the inclusion complexes nanofibrous membrane}

$\mathrm{PH}$ is an important factor that affects the ability of the sensor to detect determinand, thus the inclusion complexes nanofibrous membrane was immersed in aqueous solution and $\mathrm{F}^{-}$solution of different $\mathrm{pH}$ to test its $\mathrm{pH}$ stability. As illustrated in Figure 7, the black dots represent the fluorescence intensity of the inclusion complexes nanofibrous membrane in aqueous solution of $\mathrm{pH} 3$ to 12 , it could be seen that the fluorescence intensity was stable from pH 6 to 10, excessive acidity and alkalinity both reduced the fluorescence intensity. In addition, the red dots represent the fluorescence intensity of the inclusion complexes nanofibrous membrane in $\mathrm{F}^{-}$solution from $\mathrm{pH} 3$ to 12 . As can be seen from the figure, $\mathrm{F}^{-}$all quenched the fluorescence under different $\mathrm{pH}$ conditions, hence the experimental data show that the inclusion complexes nanofibrous membrane has certain $\mathrm{pH}$ stability from $\mathrm{pH} 6$ to 10, and verified its potential practical application value. 


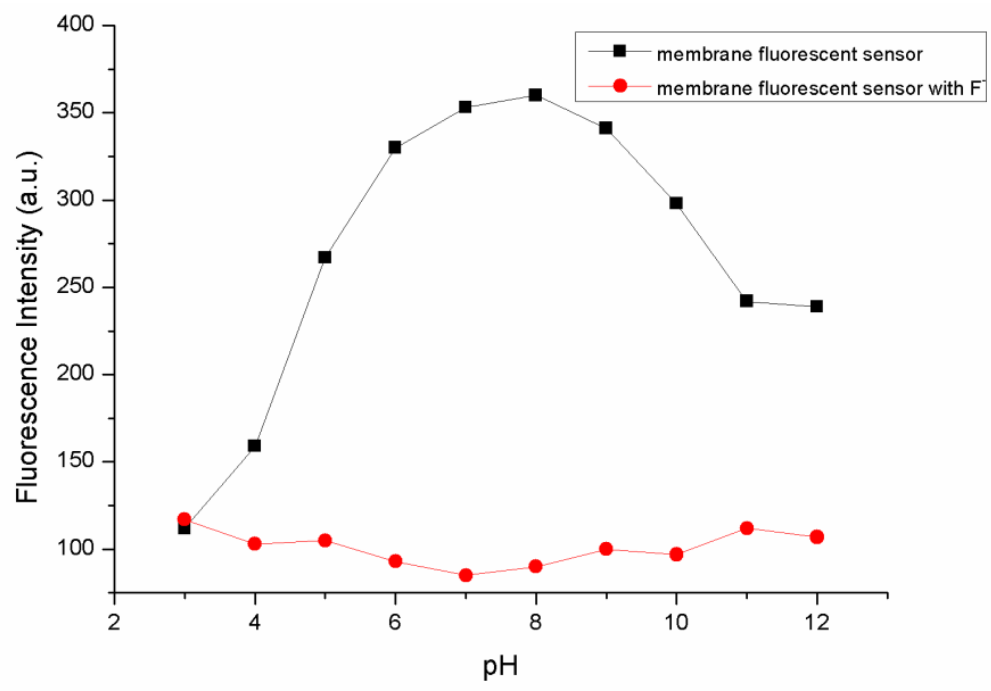

Figure 7: Effect of $\mathrm{pH}$ on fluorescence intensity of the inclusion complexes nanofibrous membrane before and after recognition of $\mathrm{F}^{-}$

\subsection{Adsorption kinetics of $F^{-}$onto the inclusion complexes nanofibrous membrane}

The inclusion complexes nanofibrous membrane provides a porous reticulation structures, which distinctly accelerate $\mathrm{F}^{-}$to approach the fluorescence sensor groups in the inclusion complexes nanofibrous membrane, meanwhile the specific porous structure also enhanced the adsorption performance of the nanofibrous membrane [19]. The equilibrium adsorption amounts were investigated by adsorption isotherm and Langmuir adsorption curve. The inclusion complexes nanofibrous membrane was cut as $0.8 \mathrm{~cm} \times 1.5 \mathrm{~cm}$, then infiltrated in $\mathrm{F}^{-}$solutions for $24 \mathrm{~h}$ in diverse concentrations severally. Afterwards, the residual concentration of $\mathrm{F}^{-}$ was surveyed by anion chromatograph. The equilibrium adsorption capacities in different $\mathrm{F}^{-}$equilibrium concentrations were shown in Figure 8a, it was illustrated that the adsorption quantity of $\mathrm{F}^{-}$increased obviously along with the increasing $\mathrm{F}^{-}$until the concentration reached $80 \mathrm{mg} \mathrm{L}^{-1}$, subsequently the adsorption quantity leveled off. The reason for the change of adsorption curve could be owing to the binding sites for $\mathrm{F}^{-}$ in the inclusion complexes nanofibrous membrane became saturated, then redundant $\mathrm{F}^{-}$cannot be occupied, and result in the steady of adsorption quantity [20]. The Langmuir adsorption equation was given as follows, to analyze the experimental adsorption equilibrium data of the inclusion complexes nanofibrous membrane to $\mathrm{F}^{-}[21]$.

$\frac{C_{e}}{q_{e}}=\frac{1}{K_{L} q_{m}}+\frac{C_{e}}{q_{m}}$

In the equation, $\mathrm{q}_{\mathrm{e}}$ represents the equilibrium quantity of $\mathrm{F}^{-}$adsorbed in the inclusion complexes nanofibrous membrane, $\mathrm{C}_{\mathrm{e}}$ represents the equilibrium concentration, $\mathrm{q}_{\mathrm{m}}$ represents saturation adsorption capacity and $\mathrm{K}_{\mathrm{L}}$ represents binding energy, thereinto, $\mathrm{q}_{\mathrm{m}}$ and $\mathrm{K}_{\mathrm{L}}$ are related to the Langmuir constants. As illustrated in Figure $8 b, C_{e} q_{e}^{-1}$ and $C_{e}$ were in a linear relationship $\left(R^{2}>0.99\right)$. According to the Langmuir theory, every single receptor only absorbed one donor, so the adsorption appears in the inclusion complexes nanofibrous membrane is monoptychial. ${ }^{17}$ Thus the $\mathrm{F}^{-}$adsorption capacity could be calculated from linear equation between $\mathrm{C}_{\mathrm{e}} \mathrm{q}_{\mathrm{e}}^{-1}$ and $\mathrm{C}_{\mathrm{e}}$ in Figure $8 \mathrm{~b}$, and it is $16.67 \mathrm{mg} / \mathrm{g}$ of the inclusion complexes nanofibrous membrane to $\mathrm{F}^{-}$(Table 1). 

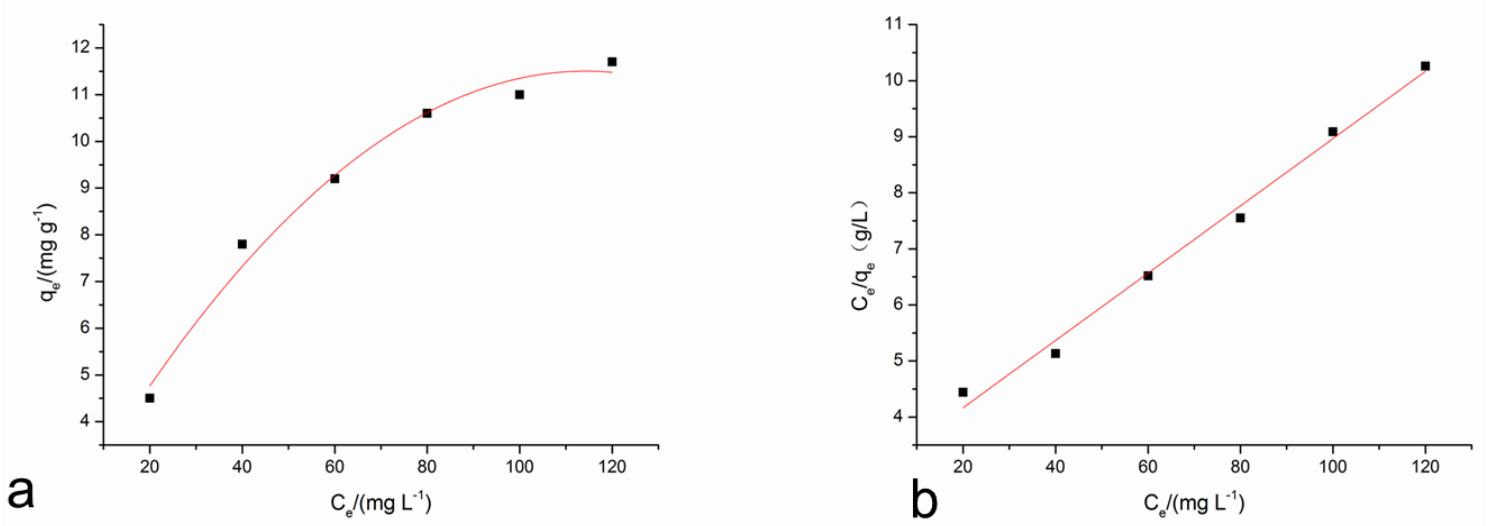

Figure 8: Adsorption isotherm plot of $\mathrm{F}^{-}$on the inclusion complexes nanofibrous membrane (a) and Langmuir plot of $\mathrm{F}^{-}$ on the inclusion complexes nanofibrous membrane (b)

Table 1: The Langmuir constants for $\mathrm{F}^{-}$on the inclusion complexes nanofibrous membrane

\begin{tabular}{cccc}
\hline anion & $\mathrm{K}_{\mathrm{L}} / \mathbf{L ~ m g}^{-1}$ & $\mathbf{q}_{\mathbf{m}} / \mathbf{m g ~ g}^{-1}$ & $\mathbf{R}^{\mathbf{2}}$ \\
\hline $\mathrm{F}^{-}$ & 0.0202 & 16.67 & 0.9960 \\
\hline
\end{tabular}

\section{CONCLUSION}

In conclusion, we have fabricated functionalized inclusion complexes nanofibrous membrane via electrospinning and host-guest interaction, the identification groups on the surface of the membrane afford the fluorescent sensor good sensitivity and selectivity for $\mathrm{F}^{-}$, in addition, the porous reticulation structure with large specific surface area offers the nanofibrous membrane good adsorption ability for F'. We believe these unique advantages make the fluorescent sensor have potential application value in the future.

\section{ACKNOWLEDGMENTS}

The authors gratefully acknowledge the support of Jilin Provincial Department of Science and Technology Outstanding Youth Talent Fund Project (20190103036JH), Jilin Provincial Education Department "the 13th Five-Year Plan" Science and Technology Research Project (JJKH20181115KJ and JJKH20200738KJ), Undergraduate Entrepreneurship Project of Changchun University of Science and Technology, and the Youth Fund Project of Changchun University of Science and Technology (XQNJJ-2019-12).

\section{BIBLIOGRAPHY}

[1] YANG, L., DONG, T., REVANKAR, H. M., et al., "Recent progress on fluorination in aqueous media", Green Chemistry, v. 19, n. 17, pp. 3951-3992, Jul. 2017.

[2] WANG, L.T., XIE, Y.H., YANG, J.L., et al., "Insight into mechanisms of fluoride removal from contaminated groundwater using lanthanum-modified bone waste", RSC Advances, v. 85, n.7, pp. 5429154305, Nov. 2017.

[3] RAN, X., GAO, Q.Q., ZHANG, Y., et al., "Colorimetry and phase transition characteristics in sensing fluoride anion based on hydrazide organogelators", RSC Advances, v. 88, n.7, pp. 56016-56022, Dec. 2017.

[4] ALLED, M., FERNANDEZ, A., EDLER, K.J., et al., "Azulene-boronate esters: colorimetric indicators for fluoride in drinking water”, Chemical Communications, v. 53, n.93, pp. 12580-12583, Nov. 2017.

[5] TURAN, I.S., SEVEN, O., AYAN, S., et al., "Amplified chemiluminescence signal for sensing fluoride ions", ACS Omega, v. 7, n. 2, pp. 3291-3295, Jul. 2017.

[6] WINCK, A.L., SANTOS, J.C.V., LENZ, D.M., et al., "Development and characterization of gas sensors using thin films of polyaniline as active layer", Revista Materia, v. 23, n. 4, pp. 12259-12268, Sep. 2018.

[7] YANG, T., HOU, P., ZHENG, L.L., et al., "Surface-engineered quantum dots/electrospun nanofibers as a networked fluorescence aptasensing platform toward biomarker", Nanoscale, v. 43, n. 9, pp. 17020-17028, Nov. 2017. 
[8] CHANDRAN, G.T., LI, X.W., Ogata, A., et al., "Electrically transduced sensors based on nanomaterials (2012-2016) ", Analytical Chemistry, v. 89, n. 1, pp. 249-275, Jan. 2017.

[9] RICHARDSON, J., CUI, J.W., BJORNMALM, M., et al., "Innovation in layer-by-layer assembly", Chemical Reviews, v. 116, n. 23, pp. 14828-14867, Dec. 2016.

[10] LU, C.L., XU, Z.C., CUI, J.N., et al., "Ratiometric and highly selective fluorescent sensor for cadmium under physiological $\mathrm{pH}$ range: a new strategy to discriminate cadmium from zinc", Journal of Organic Chemistry, v. 72, pp. 3554-3557, Apr. 2007.

[11] WANG, W., WANG, X.L., YANG Q.B., et al., "A reusable nanofibrous film chemosensor for highly selective and sensitive optical signaling of $\mathrm{Cu}^{2+}$ in aqueous media.", Chemical Communications, v. 49, n. 42 , pp. 4833-4835, Apr. 2013.

[12] WANG, W., WONG, N.K., SUN, M.D., et al., "Regenerable fluorescent nanosensors for monitoring and recovering metal ions based on photoactivatable monolayer self-assembly and host-guest interactions", ACS Applied Materials and Interfaces, v.7, n. 16, pp. 8868- 8875, Apr. 2015.

[13] BIAN, Q., WANG, W.S., WANG, S.T., et al. "Light-triggered specific cancer cell release from cyclodextrin/azobenzene and aptamer-modified substrate", ACS Applied Materials \& Interfaces, v. 40, n. 8, pp. 27360-27367, Oct. 2016.

[14] LIU, B., TIAN, H., "A selective fluorescent ratiometric chemodosimeter for mercury ion", Chemical Communications, v. 25, n. 7, pp. 3156-3158, Jul. 2005.

[15] ZHOU, C., LIU, H., "A novel nanofibrous film chemosensor for highly selective and sensitive optical signaling of $\mathrm{Zn}^{2+}$, , Journal of the Brazilian Chemical Society, v. 28, n. 10, pp. 1947-1952, Oct. 2017.

[16] MIN, M.H., WANG, X.F., CHEN, Y.M., et al., "Highly sensitive and selective $\mathrm{Cu}^{2+}$ sensor based on electrospun rhodamine dye doped poly(ether sulfones) nanofibers", Sensors and Actuators B: Chemical, v. 188, n. 7, pp. 360-366, Nov. 2013.

[17] JIAO, S., WANG, X.C., SUN, Y.H., et al.,“A novel fluorescein-coumarin-based fluorescent probe for fluoride ions and its applications in imaging of living cells and zebrafish in vivo", Sensors and Actuators B, v. 262, pp. 188-194, Jun. 2018.

[18] CHANDRAN, G.T., LI, X.W., OGATA, A., et al. "Electrically transduced sensors based on nanomaterials (2012-2016)", Analytical Chemistry, v. 89, n. 1, pp. 249-275, Nov. 2017.

[19] ZHAO, Y., JIANG, C., HU, C., et al. "Large-scale spinning assembly of neat, morphology-defined, graphene-based hollow fibers", ACS Nano, v. 7, n. 3, pp. 2406-2412, Feb. 2013.

[20] SAEED, K., HAIDER, S., OH, T.J., et al., "Preparation of amidoxime-modified polyacrylonitrile (PANoxime) nanofibers and their applications to metal ions adsorption", Journal of Membrane Science, v. 322, n. 2, pp. 400-405, Sep. 2008.

[21] ZHOU, C., ZHANG, Y.N., LIU, H., "A novel nanofibrous film chemosensor for detecting and adsorbing Fe ${ }^{3+»}$, Journal of the Brazilian Chemical Society, v. 29, n. 3, pp. 457-462, Mar. 2018.

\section{ORCID}

Huan Zhang

Chen Zhou

Jing Sun

Xiao Li

Juan Tang https://orcid.org/0000-0001-7239-2830

https://orcid.org/0000-0001-6782-2277 (Corresponding Author )

https://orcid.org/0000-0001-8407-5592

https://orcid.org/0000-0002-5518-5044

https://orcid.org/0000-0001-9801-4774 